\title{
Morphological and molecular characterization of Cercospora zebrina from black bindweed in Iran
}

\author{
Bakhshi $\mathrm{M}^{1}$, Arzanlou $\mathrm{M}^{2^{*}}$ and Babai-Ahari $\mathrm{A}^{3}$ \\ ${ }^{1}$ PhD Student of Plant Pathology, Plant Protection Department, Faculty of Agriculture, University of Tabriz, PO Box: \\ 5166614766, Iran. \\ ${ }^{2}$ Assistant Professor of Plant Pathology and Mycology, Plant Protection Department, Faculty of Agriculture, University \\ of Tabriz, PO Box: 5166614766, Iran. \\ ${ }^{3}$ Professor of Plant Pathology, Plant Protection Department, Faculty of Agriculture, University of Tabriz, PO Box: \\ 5166614766, Iran.
}

Bakhshi M, Arzanlou M, Babai-Ahari A 2012 - Morphological and molecular characterization of Cercospora zebrina from black bindweed in Iran. Plant Pathology \& Quarantine 2(2), 125-130, doi $10.5943 / \mathrm{ppq} / 2 / 2 / 5$

Cercospora isolates were recovered from Fallopia convolvulus showing leaf spot disease symptoms. Based on phenotypic features and partial sequence data from calmodulin and elongation factor 1- $\alpha$ genes the isolates were identified as Cercospora zebrina. C. zebrina is characterized for the first time from a new host plant based on phenotypic and DNA data. Morphology, phylogeny and host range of this species is discussed in the first attempt to circumscribe cercosporoid fungi of Iran from pure culture.

Key words - cercosporoid fungi - Fallopia convolvulus - host range - hyphomycetes - leaf spot

\section{Article Information}

Received 3 July 2012

Accepted 18 July 2012

Published online 5 September 2012

*Corresponding author: Mahdi Arzanlou - e-mail - Arzanlou@ @otmail.com

\section{Introduction}

Cercospora Fresen. sensu lato is one of the largest genera of hyphomycetes. Species in this genus are important pathogens responsible for severe damage on beneficial plants such as maize, rice, wheat grasses, vegetables, forest trees and ornamentals (Goodwin et al. 2001, Crous \& Braun 2003). The genus Cercospora was established by Fresenius in 1863 (Braun 1995). Cercospora has since been split into several genera on the basis of criteria such as conidiomatal structure, and morphological features of the mycelia, conidiophores, conidiogenous cells, and conidial pigmentation (Crous \& Braun 2003). Crous \& Braun (2003) in their revision of cercosporoid fungi based on sequence data and reassessment of morphological characters, recognized four true cercosporoid genera, viz. Cercospora, Pseudocercospora Speg., Passalora Fr. and Stenella Syd., and several other morphologically similar genera. In the past, species definition within the genus Cercospora was mainly based on host plant association (Chupp 1954) and it is still used for species definition in this genus. However, there is a paucity of knowledge on the degree of host specificity amongst different Cercospora species; some taxa such as $C$. apii, the type species of the genus, have been reported to occur on different unrelated plant families (Crous \& Braun 2003). Hence, the identity of many species with more or less similar morphology, described only based on host plant association criterion remains questionable. With the advent of molecular techniques it is now feasible to figure out species boundaries and biodiversity of this genus as well. Whether the current number of Cercospora species will increase or will shrink remains to be answered. Generally speaking, in fungal groups where the number of species are 
more than the number of unique morphological features, the trend is for a drastic increase in species number when DNA sequence based approaches are applied for species delineation (Crous et al. 2009).

Bakhshi et al. (2012) listed 89 cercosporoid species from Iran, including 29 Cercospora species. However, most of these species have been described on the basis of morphological characteristics provided by the genus concept of Chupp (1954) and there are no living cultures available for these taxa to be confirmed by a molecular approach to classification (Crous \& Braun 2003). In the present paper we characterize C. zebrina from a new host plant based on phenotypic and DNA data, which is the first attempt to circumscribe cercosporoid fungi of Iran from pure culture.

\section{Methods}

\section{Isolates and morphology}

Leaves of Fallopia convolvulus (L.) Á. Löve (black bindweed) showing leaf spot were collected from Firouragh in the Khoy region (West Azerbaijan Province, Iran) during September 2010. Single spore cultures were established using single spore technique as described by Arzanlou \& Bakhshi (2011), in brief, under a stereomicroscope a mass of conidia and conidiophores were picked up from the surface of leaf lesion using a wetted sterile inoculation needle and then floated in $10 \mathrm{ml}$ sterile distilled water and spread on $2 \%$ malt extract agar (MEA, Himedia, India), supplemented with $2 \mathrm{ml}$ of $20 \%$ lactic acid/litre. Plates were incubated in a slanted position overnight and germinated conidia were transferred to new MEA plates under a stereomicroscope. Pure cultures were deposited in the Culture Collection of Tabriz University (CCTU). Colony morphology and microscopic features were examined from the cultures grown on 2\% MEA. Microscopic slides were prepared from stromata, conidiophores and conidia in lactic acid. Characters such as, presence or absence of stromata and their development, pigmentation of conidia, conidiophores and conidiogenous loci (scars) were used to identify the species. Wherever possible, 30 measurements per relevant microscopic structure were determined. $95 \%$ confidence intervals were derived for the measurements with the extreme values given in parentheses. Drawings were made using a drawing tube attached to an Olympus BX41 microscope. Colony colours (surface and reverse) were assessed after 30 days on MEA at $25^{\circ} \mathrm{C}$ in the dark, using the colour chart of Rayner (1970).

\section{DNA phylogeny}

The protocol of Moller et al. (1992) was used to isolate genomic DNA from fungal mycelium of monoconidial cultures grown on MEA in Petri dishes. The primers ITS1 and ITS4 (White et al. 1990) were used to amplify part (ITS) of the nuclear rRNA operon spanning the 3 ' end of the 18S rRNA gene, the first internal transcribed spacer (ITS1), the 5.8S rRNA gene, the second ITS region and the 5, end of the 28S rRNA gene. To obtain additional sequence information, part of the calmodulin gene (CAL) was amplified with primers CAL-228F and CAL-737R (Carbone \& Kohn 1999) and part of elongation factor gene was amplified using EF728 (Carbone \& Kohn 1999) and EF2 (Jacobs et al. 2004) primer set. The reaction mixture and PCR conditions for the ITS and calmodulin gene were the same as Crous et al. (2004) and for the elongation factor, PCR was carried out in a final volume of $12.5 \mu \mathrm{l}$ containing $10-15 \mathrm{ng}$ genomic DNA, $1.25 \mu$ of $10 \mathrm{X}$ reaction buffer, $60 \mu \mathrm{l}$ of $1 \mathrm{mM}$ dNTPs, $2 \mathrm{mM} \mathrm{MgCl} 2,0.2 \mathrm{pM}$ of each primer, $0.5 \mu \mathrm{LSMO}$, and $0.5 \mathrm{U}$ Taq Polymerase. The reaction was performed on a GeneAmp PCR System 9700 (Applied Biosystems, Foster City, CA) with cycling conditions consisting of $5 \mathrm{~min}$ at $96{ }^{\circ} \mathrm{C}$ for primary denaturation, followed by 40 cycles of $94{ }^{\circ} \mathrm{C}$ for $30 \mathrm{~s}, 52{ }^{\circ} \mathrm{C}$ for $30 \mathrm{~s}, 72^{\circ} \mathrm{C}$ for $60 \mathrm{~s}$, with a final extension at $72{ }^{\circ} \mathrm{C}$ for $7 \mathrm{~min}$. The obtained sequences were compared to the sequences available in NCBI's GenBank nucleotide (nr) database using a megablast search.

\section{Results}

\section{DNA Phylogeny}

Blast search of ITS-rDNA against GenBank nucleotide (nr) database did not differentiate our isolates from the other 


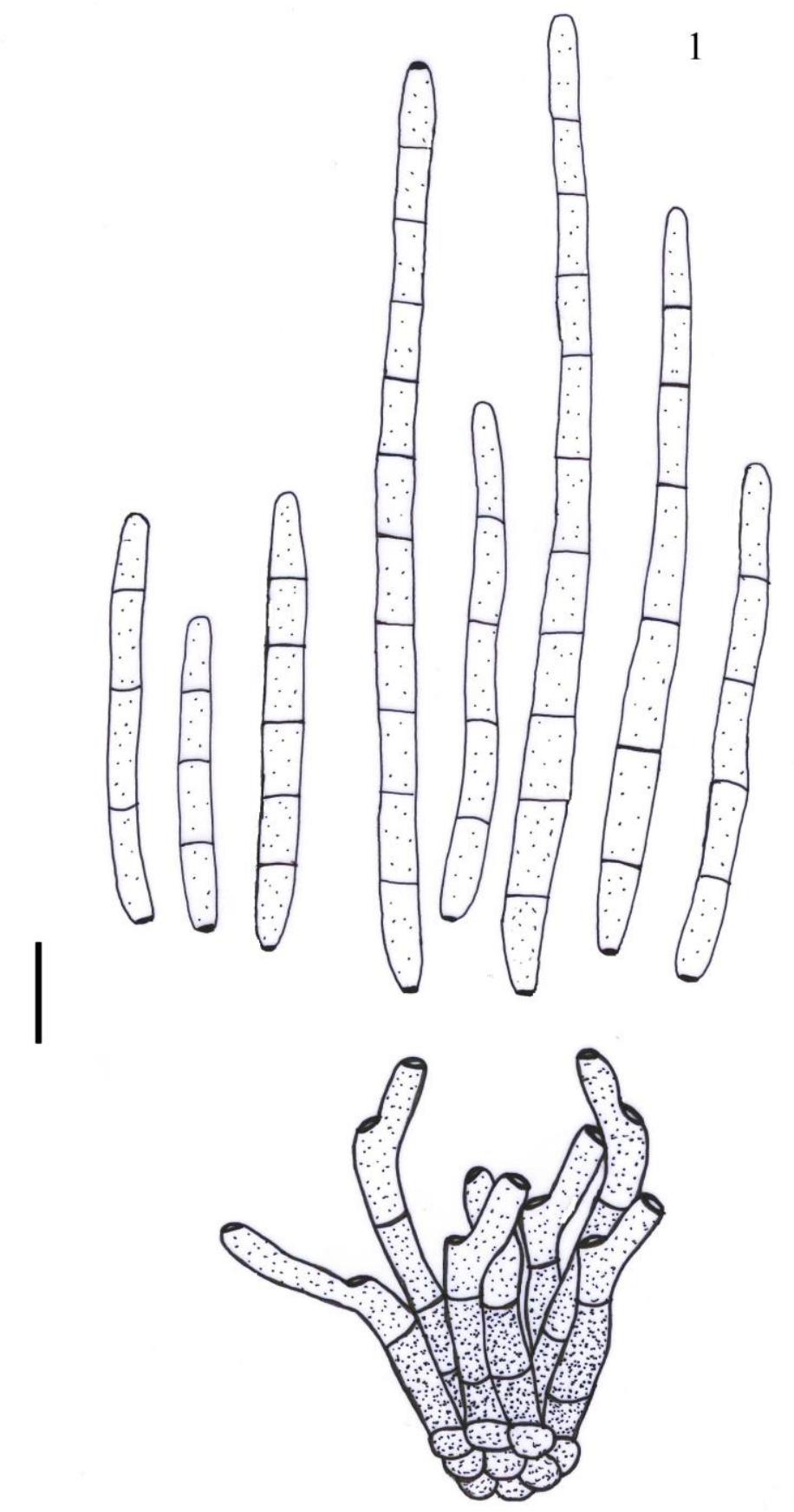

Fig. 1 - Conidiophores and conidia of Cercospora zebrina Pass. Bar $=10 \mu \mathrm{m}$.

Cercospora species in GenBank. Blast search of both ef- $1 \alpha$ and calmodulin genes in GenBank also was of no help in species identification. A comparison of obtained sequences, with Pedro Crous's personal DNA sequences database for Cercosporoid fungi, located at evolutionary phytopathology group, CBS-KNAW Fungal Biodiversity Centre, Utrecht, The Netherlands, showed that our isolates cluster with Cercospora zebrina clade. Sequences are available in GenBank with the accession numbers: ITS $=$ JX390615, ef- $1 \alpha=$ JX413117 and calmodulin $=$ JX413118).

\section{Morphological and cultural features}

Cercospora zebrina Pass. 1877, Hedwigia 16: 124

Figs 1- 8

Leaf spots circular grey to brown in colour with undefined margins. Mycelium internal. Conidiophores arising in fascicles of 4-10, emerging through stomata, erect, conidiophores $(4-) 5(-6) \times(30-) 43-52(-70)$ $\mu \mathrm{m}$, medium brown, becoming pale brown towards the apex, straight and subcylindric to geniculate-sinous, unbranched, 1-4-septate, wall somewhat thickened. Conidiogenous cells integrated, terminal, occasionally unilocal, 
usually multilocal, sympodial; loci subcircular, conspicuous, thickened, darkened, refractive, 2.5-3 $\mu \mathrm{m}$ wide. Conidia solitary, occasionally in short chains, cylindrical, not acicular, 3-5 $\times$ (25-)53-70(-100) $\mu \mathrm{m}, 2-10$-septate, usually 3-4-septate, hyaline, thin-walled, smooth, apex rounded, base subtruncate; hila slightly thickened and darkened.

Cultural characteristics: Colonies on MEA at $25^{\circ} \mathrm{C}$ in the dark reaching $70 \mathrm{~mm}$ diam after 30 days, erumpent, with sparse aerial mycelium; margins smooth; surface greyolivaceous with sectors of iron-grey; reverse olivaceous-black; colonies fertile.

Specimen examined: Iran, West Azerbaijan, Khoy, Firouragh on leaves of Fallopia convolvulus (L.) Á. Löve, Jul. 2010, coll. M. Arzanlou. Living culture CCTU 10.

\section{Discussion}

Until now, 11 species of Cercospora s. str. have been recorded on plant species in the family Polygonaceae: $C$. apii Fresen., $C$. bicolor Winter, C. beticola Sacc., C. eriogoni Ellis \& Everh., C. fagopyri Nakata \& Takim, C. gorakhpurensis Bhartiya et al., $C$. polygonacea Ellis \& Everh., C. peckiana Chupp, C. polygoni-multiflori Chen \& Chi, $C$. rhei Roum. and C. tripolitana Sacc. \& Trotter (Crous \& Braun 2003). The morphological characteristics of the isolates from $F$. convolvulus are in agreement with those of $C$. zebrina. In this species, conidia are more or less cylindrical with obtuse apices. Blast search result of ITS sequence data was of no help in confirming the identity of C. zebrina. There are several reports available that ITS region is not diverse enough to resolve species boundaries in the genus Cercospora (Crous et al. 2009). The same results obtained with blast search analysis of sequence data from calmodulin and ef- $1 \alpha$ genes. The reason for this failure is that there are few sequences of Cercospora species for other loci than ITS-rDNA region available in GenBank. Comparison of the obtained sequence data with Pedro Crous's personal DNA sequences database for Cercosporoid fungi, further confirmed the identity of species as $C$. zebrina. F. convolvulus is type host of $C$. polygonacea, which is, however, $C$. apii-like, i.e. with long acicular conidia with pointed apex, although small and young conidia may also be subcylindrical (Crous \& Braun 2003). C. zebrina has been reported to occur mainly on legumes; however, there are some reports of C. zebrina on different plant families such as Scrophulariaceae and Bignoniaceae (Crous \& Braun 2003). With this report we add $F$. convolvulus as a new host for $C$. zebrina in the family Polygonaceae. C. zebrina has already been reported from Iran on Medicago sativa $\mathrm{L}$. (Ebrahimi \& Minassian 1973), however, the authors did not provide a description for this species.

With these results it is now clear that host plant association criterion and morphology alone are not satisfactory for species definition within the genus Cercospora and may lead to misidentification. The need for sequence data is indispensable for species identification in Cercospora (Uwe Braun, personal communication). This is indeed interesting that C. zebrina infects plant species in different plant families. Whether $F$. convolvulus is a true natural host for $C$. zebrina or the pogo-stick hypothesis postulated by Crous \& Groenewald (2005) is playing a role, remains to be answered. Host jumping is another phenomenon which may explain infection of $F$. convolvulus by $C$. zebrina. This phenomenon involves the ability of a pathogen to infect a new host which is genetically distant from the original host plant (Stukenbrock \& McDonald 2008) e.g. Fabaceae and Polygonaceae. The phenomenon of wide host range might hold true for many other Cercospora species. There are such data available for $C$. beticola and $C$. apii which occur on different unrelated plants (Crous \& Braun 2003). Nevertheless, for most species in this genus there is no data available on the degree of host specificity and hostpathogen interaction. The main reason for the lack of data on pathogen-host interaction in Cercospora is the low rates of success with the induction of sporulation in cercosporoid fungi on synthetic media (Arzanlou et al. 2007, Bakhshi et al. 2011). Many of the cercosporoid fungi, especially Cercospora species loose the sporulation potential soon after sub-culturing (Arzanlou et al. 2007, 2008). Alternative inoculation methods should be developed in order to facilitate pathogen-host interaction studies. Bakhshi et al. (2011) used mycelial suspension to inoculate sugar beet plants under 

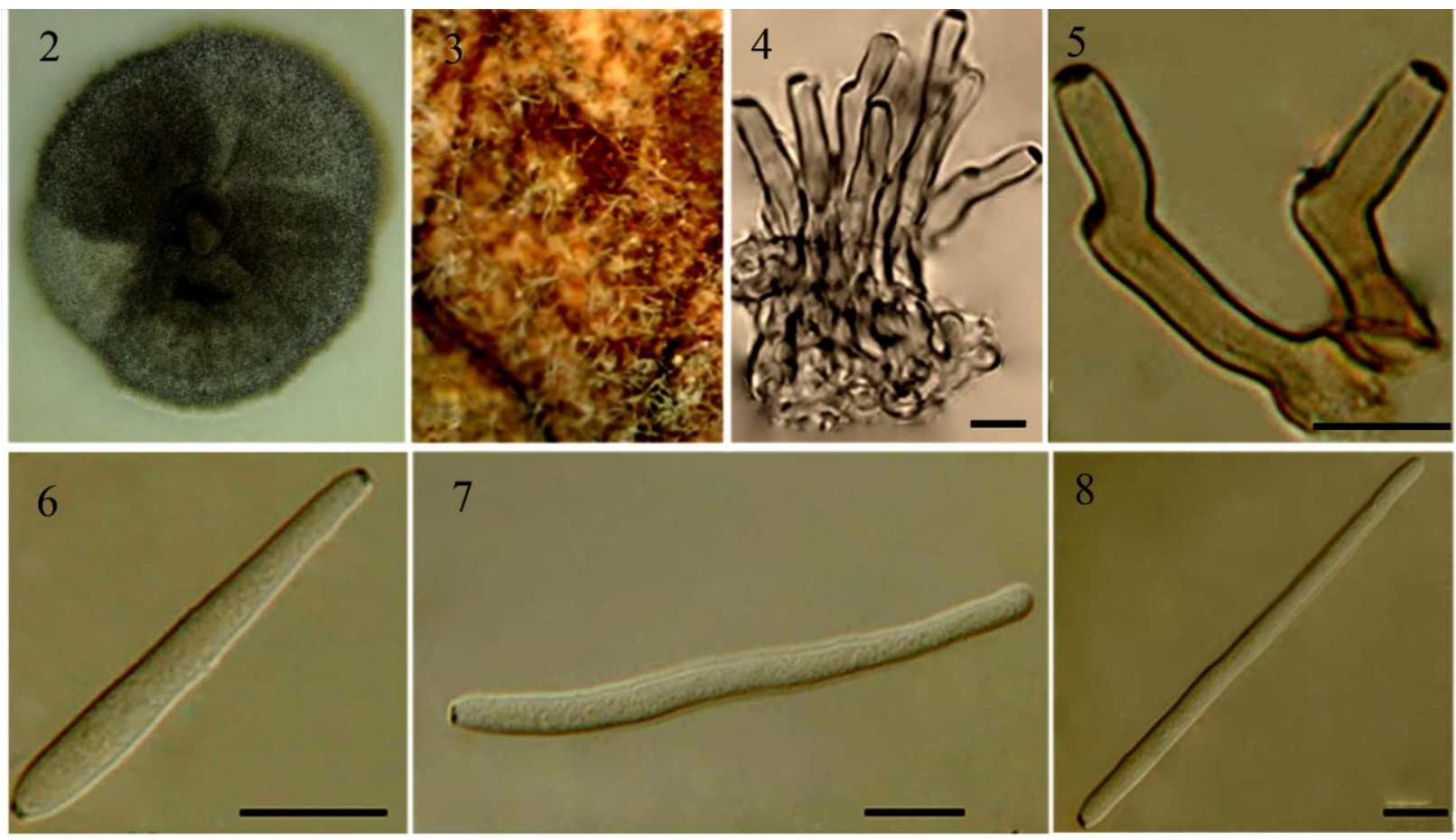

Figs 2-7 - Cercospora zebrina. 2 30-day old colony on MEA. 3 Conidiophore fascicles on leaf surface. 4 Conidiophore fascicles. 5 Conidiophore with darkened conidiogenous locus. 6, 7, 8 Conidia in vivo. Bars $=10 \mu \mathrm{m}$.

greenhouse conditions with $C$. beticola. Typical symptoms of cercospora leaf spot developed on inoculated sugar beet plants. Such protocols should be optimized for the other cercosporoids as well. Hence, we are currently elucidating host range of C. zebrina, C. beticola and C. apii isolates with inoculation studies on different hosts.

\section{Acknowledgements}

The authors thank Prof. Uwe Braun and Dr Ewald Groenewald for their help to confirm the identity of the Cercospora isolates. The Research Deputy of the University of Tabriz and the Studienstiftung Mykologie are thanked for financial support.

\section{References}

Arzanlou M, Abeln ECA, Kema GHJ, Waalwijk C, Carlier J, Vries Ide, Guzman M, Crous PW 2007 - Molecular diagnostics for the Sigatoka disease complex of banana. Phytopathology 97, 1112-1118.

Arzanlou M, Bakhshi M 2011 - Microcyclospora rumicis, a new species on Rumex crispus from Iran. Mycotaxon 118, 181186.
Arzanlou M, Groenewald JZ, Fullerton RA, Abeln ECA, Carlie J, Zapater MF, Buddenhagen IW, Viljoen A, Crous PW 2008 - Multiple gene genealogies and phenotypic characters differentiate several novel species of Mycosphaerella and related anamorphs on banana. Persoonia 20, 19-37.

Bakhshi M, Arzanlou M, Babai-Ahari A. 2011 - Uneven distribution of mating type alleles in Iranian populations of Cercospora beticola, the causal agent of Cercospora leaf spot disease of sugar beet. Phytopathologia Mediterranea 50, 101109.

Bakhshi M, Arzanlou M, Babai-Ahari A. 2012 -Comprehensive check list of Cercosporoid fungi from Iran. Plant Pathology \& Quarantine 2, 44-55

Braun U. 1995 - A monograph of Cercosporella, Ramularia and allied genera (phytopathogenic hyphomycetes), Vol. 1. IHW-Verlag, Eching, Germany.

Carbone I, Kohn LM. 1999 - A method for designing primer sets for speciation studies in filamentous ascomycetes. Mycologia 91, 553-556.

Chupp C. 1954 - A monograph of the fungus 
genus Cercospora. Ithaca, New York.

Crous PW, Braun U. 2003 - Mycosphaerella and its anamorphs: 1. Names published in Cercospora and Passalora. Centraalbureau voor Schimmelcultures, Utrecht, Netherlands.

Crous PW, Groenewald JZ. 2005 - Hosts, species and genotypes: opinions versus data. Australasian Plant Pathology 34, $463-470$.

Crous PW, Groenewald JZ, Pongpanich K, Himaman W, Arzanlou M, Wingfield M.J. 2004 - Cryptic speciation and host specificity among Mycosphaerella spp. occurring on Australian Acacia species grown as exotics in the tropics. Studies in Mycology 50, 457-469.

Crous PW, Verkley GJM, Groenewald JZ, Samson RA. 2009 - Fungal Biodiversity. CBS Laboratory Manual Series 1. First Ed. Centraalbureau voor Schimmelcultures, Utrecht.

Ebrahimi AGh, Minassian V. 1973 - An index of cultivated and wild plant diseases in Khuzestan. College of Agriculture, Jundi Shapur University, Ahvaz, Iran.

Goodwin SB, Dunkle LD, Zismann V. 2001 Phylogenetic analysis of Cercospora and Mycosphaerella based on the internal transcribed spacer region of ribosomal DNA. Phytopathology 91, 648-658.

Jacobs K, Bergdahl DR, Wingfield MJ, Halik $\mathrm{S}$, Seifert KA, Bright DE, Wingfield BD. 2004 - Leptographium wingfieldii introduced into North America and found associated with exotic Tomicus piniperda and native bark beetles. Mycological Research 108, 411-418.

Moller EM, Bahnweg G, Geiger HH. 1992 - A simple and efficient protocol for isolation of high molecular weight DNA from filamentous fungi, fruit bodies, and infected plant tissues. Nuclear Acid Research 20, 6115-6116.

Rayner, RW. 1970 - A mycological colour chart. Kew, Surrey, UK: CMI and British Mycological Society.

Stukenbrock EH, McDonald A. 2008 - The origins of plant pathogens in agroecosystems. Annual Review of Phytopathology 46, 75-100.

White TJ, Bruns TD, Lee SB, Taylor JW. 1990 - Amplification and sequencing of fungal ribosomal RNA genes for phylogenetics. In: PCR-Protocols and Applications - A Laboratory Manual (eds $\mathrm{N}$ Innis, D Gelfand, J Sninsky, TC White). Academic Press, New York 315-322. 